WE are informed that the slight prevalence of scarlatina around and in the school of Marlborough College had practically subsided before the completion of the term ending March 28th. The holidays have been somewhat extended to clear the way for a perfectly clean bill of health when the school reassembles on April 27th. No case of a serious character has occurred throughout the epidemic.

THE speedy establishment of three more training ships is announced, severally on the Thames, at Bangor, and at Cork. We reiterate the opinion that the Admiralty should decline to grant the loan of hulks to charitable or other societies for educational purposes, unless it be shown that, on the fitting up of such ressels, some sort of systematic attention would be paid to sanitary arrangements.

Maror BoLTon reports that a considerable improvement in the filtered water supplied to the metropolis was apparent during the February examinations, consequent on the subsidence of the floods. Notwithstanding this improvement, the deterioration of the waters of the Thames and the Lea by sewage pollution continues, and special attention is now called to the fact.

\section{THE ROYAL COLLEGE OF PHYSICIANS.}

A menting of the College of Physicians was held on Monday last, when Dr. Risdon Bennett was unanimously elected President for the ensuing year. He delivered the annual address, which was devoted to a review of the pro. gress of events concerning the College during the last twelvemonth, and a notice of the merits of the fellows deceased during that period. A vote of thanks, moved by Sir Thomas Watson, was given by the College, which also requested Dr. Bennett to publish his address. Sir Thomas Watson presented to the College, on behalf of the Rev. F. J. Holland, a copy of the late Sir Henry Holland's promiscuous papers which he left behind him for publication.

The following important, though short, report from the Leprosy Committee was adopted, and copies were ordered to be sent to the Colonial and Indian Offices for the information of Government:-

"The Committee have read the memorandum containing certain statistics of the leper establishments in Norway, prepared by Dr. Hansen, the acting director of those asylums, and forwarded through the Colonial Office to the College, with Dr. Vandyke Carter's comments thereon ; and upon which the Earl of Carnarvon has requested the opinion of the College, more especially with reference to the segregation of lepers. These statistical data, which extend over a series of years, indicate a remarkable diminution in the prevalence of leprosy in Norway during the period in which the practice of segregation has been carried out. The committee, in their report of the 9th February last, recommended segregation upon sanitary and therapentic grounds, and they consider the statistics of Dr. Hansen furnish an additional argument in favour of that recommendation. At the same time, the Committee are of opinion that there is not sufficient evidence to warrant them in accepting Dr. Hansen's explanation as to the way in which segregation operates in diminishing the amount of leprosy in Norway. It must be borne in mind that, according to Dr. Vandyke Carter's Report to the Secretary of State for India in 1873 , segregation in Norway is entirely voluntary; the lepers are allowed to receive visits from their friends, to go out of the hospital at stated intervals, and to leave it altogether when. ever they choose. The term, therefore, means nothing more than that special hospitals are provided for such patients. It is well known that Dr. Vandyke Carter and Dr. Hansen have had very extensive experience of leprosy, and have devoted much attention to its study for many years. Therefore, the observations of these gentlemen are entitled to great consideration."

The College adopted the report of the Roll Committee, recommending the issue of a new edition of the Roll in three volumes, and the College sanctioned the affixing of the College seal to the agreement between it and the editor, Dr. Munk.

The following bye-law was enacted for the first time :"Any candidate for the College licence who shall have obtained a degree in medicine or surgery at either a British, colonial, or foreign university recognised by the College, after a course of study and an examination satisfactory to the College, shall be exempt from re-examination on such subjects as the Censors' Board shall in each case consider necessary."

\section{THE SMALL-POX EPIDEMTC.}

AFTER a steady increase during the three preceding weeks, the fatal cases of small-pox in twenty of the largest English towns showed a marked decline during the week ending the 24th instant. Of the 87 deaths from small-pox then registered in these towns (23 less than those in the previous week), 76 occurred in London, 8 in Liverpool, 3 in Manchester and Salford, and not one in any of the sixteen other towns. In the outer ring of suburban districts 7 fatal cases were reported-4 occurred in West Ham, and 1 each in Edmonton, Bushey, and Stratford.

The deaths from small-pox in London, which had been 84,96 , and 100 in the three preceding weeks, declined last week to 76 , of which 33 were certified as unvaccinated, 19 as vaccinated, and 24 were " not stated" as to vaccination. Of these 76 deaths, 37 were recorded in the Metropolitan Asylum Hospitals, 3 in the Highgate Small-pox Hospital, and 2 in the temporary hospital established by the Pancras local sanitary authority; the remaining 34 fatal cases occurred in private dwellings. After distributing the hospital cases, it is reported by the Registrar-General that 11 of the deceased small-pox patients had resided in Bow, 8 in Hackney, 6 in Islington, 5 in Marglebone, and 4 each in Pancras, Southwark, and Camberwell. The fatal eases showed a marked decline both in West and South London, but the disease again showed excessive fatality in the East districts, especially in Bow. The population of Bow and Bromley is probably now about 85,000 persons, among whom 97 deaths from small-pox were registered in the first twelve weeks of this year, showing an annual rate of nearly five per 1000 persons living; whereas the average rate in the whole of London has not exceeded 1.7 for the same period. During the three weeks ending the 24th instant, as many as 40 deaths from small-pox occurred in Bow and Bromley, equal to an annual rate of 8 per 1000 .

The opening of a new hospital at Deptford makes the seventh institution now in use for the reception of small-pox patients. These seven hospitals contained 959 patients on the 24th inst., against numbers increasing steadily from 898 to 952 at the end of the four preceding weeks ; this number included 150 convalescents, of whom 83 were at Limehouse and 67 at Fulham. The number of patients under treatment, therefore, does not show a decline; and 243 new cases were admitted during the week, against 223 and 212 in the two preceding weeks.

\section{Correspondente.}

\section{"Audi alteram partem." \\ CLINICAL SURGERY IN LONDON AND EDINBURGH \\ To the Editor of THE LANCET.}

SIR, - I have to thank your correspondents of the 10th inst. for the temperate, nay kindly, tone of their comments upon my reply to the address of the medical students of Edinburgh, and I am further obliged to them for affording me an opportunity of saying some words of explanation. The feeling which has been excited by my remarks depends, I venture to believe, entirely on misunderstanding. The 
criticisms in your journal having appeared without the text of my statement having been published in your columns, I must trespass on your indulgence for the following somewhat lengthy quotation :-

"I said, gentlemen, on entering upon my office here that I believed that this chair, if properly conducted, as it had been by my lamented predecessor, was more potent for good than any other chair in the medical curriculum; and I hold to that opinion. We have in surgery, as compared with physic, the extreme advantage that, whereas the diseases with which the surgeon has to deal are the same in essential nature as those with which the physician deals, yet, while the physician must walk comparatively in the dark, and act from inference rather than from direct observation, the surgeon sees what he does, so that we are able in a class like this to teach by demonstration on the actual living flesh and blood of our patients those great principles of patbology and practice which apply alike to medicine and to surgery. Now, gentlemen, I say that this gives to clinical surgery, if properly conducted, an intensity of interest and an opportunity of instruction which no other chair in the curriculum possesses. But if I turn to London, and ask how instruction in clinical surgery is conducted there, I find that, not only according to my own experience as a London student, which I once was, but also from the universal testimony of foreigners who visit there, and then come here, it is, when compared with our system here, a mere sham.

The magnificent opportunities of demonstrative teaching presented by clinical surgery are, to a great extent, neglected."

Now I freely admit that the latter parts of this extract, if read apart from what preceded them, and without considering the circumstances in which they were uttered, might well excite amazement and indignation. But, on referring to the earlier portion, and especially to the words which I have now italicised, and bearing in mind that $I$ was addressing my class with reference to the question whether I might be induced to give up my professorship here in exchange for a position with similar title elsewhere, it will be seen that I was alluding to clinical surgery as taught in lectures, and not at all to clinical surgical instruction conducted otherwise. Thus, all the five surgeons of our infirmary teach assiduously at the bedside in their daily visits, and our five house-surgeoncies and very numerous clerkships and dresserships afford invaluable opportunities for persunal clinical study and experience, while the policlinique of our dispensaries constitutes a very useful field for clinical training in the Edinburgh school. But to those matters, most important though they are, my remarks had no reference whatever. Similarly, I look back with gratitude to the valuable bedside instruction which I received at University College, and to the priceless privileges of practical training which I enjoyed in hospital offices in that institution; and I am well aware that the students of all the London hospitals have, in varying degrees in the various schools, corresponding advantages in the ward and in the out-patients' room. Such privileges of London students my remarks were certainly not intended to deny or to disparage, nor do I imagine that those whom I addressed were likely to give them such an interpretation. To them I spoke in the freedom and confidence of the class-room, and gave them my reasons for regarding the chair of Clinical Surgery in the University of Edinburgh as so superior in efficiency to any corresponding position at present existing in London, that no consideration would induce me to exchange the one for the other. For them alone was my statement intended, and it was only when $I$ saw the papers next morning that I had any idea that a reporter had been present in the theatre.

But although my remarks were not meant for publication, I cannot but feel surprised at the misapprehension which has prevailed regarding them. Not only have I been supposed to deny that valuable teaching in clinical surgery goes on in London schools, but by some of my critics it has been imagined that I have charged individual teachers in the metropolis with negligence, or something worse; whereas it is, as I should have thought, plain enough that the very point of my observations was directed against the system of the London Chairs of Clinical Surgery, not their occupants, with whom it would be as presumptuous as it would be offensive for me to challenge a comparison. When, therefore, Mr. Thomas Smith requests me to "withdraw" my "f hard words against teachers of clinical surgery in
London," I venture to think he has gone as wide of the mark in one direction as Mr. Leslie has in the other, when he describes an instructive visit in a ward of the London Hospital.

The only way in which I can account for such mistakes is by supposing that the position of the Edinburgh chair is not at all generally understood in London, and seeing that this matter has, though without any intention on my part, become the subject of discussion in the medical journals, I am compelled in self-defence to state as shortly as I can what the circumstances of that chair really are. Until quite recently, when Glasgow has been following her example, the University of Edinburgh stood alone, I believe, among British schools of medicine, though by no means singular as compared with Continental schools, in regarding the teaching of clinical surgery in lectures as a task demanding the best energies of any teacher, and in making this duty the subject of a distinct professorial charge on the same footing in every respect as a systematic chair. Indeed the Chair of Clinical Surgery existed in the University of Edinburgh before that of the Principles and Practice was instituted. The other great fact conducing to its efficiency was the introduction by Mr. Syme of the demonstrative system of teaching in the theatre, the immense advantages of which he had witnessed as a young man on a visit to the Continental schools; the patients whose cases are discussed being brought in succession before the class, when the pathological features are pointed out, a careful diagnosis instituted, and the treatment fully considered, and except where major operations are involved, put in practice then and there. The often-quoted words of Horace-

Segnius irritant animos demissa per aurem, Quam quæ sunt oculis subjecta fidelibus-

have here peculiar force, because the objects used in this demonstrative teaching are invested with the most intense interest, awakening the sympathies as well as the intelli. gence of the spectators. And the result of this twofold peculiarity of the Edinburgh chair is that the professor, devoting his undivided energies to teaching twice a week in this demonstrative manner a cliss entirely under his own control, and as regular in attendance as in any systematio course, bas the opportunity during a winter session of building up in the minds of his students a solid fabric of sound principles indelibly impressed. This it is which constitutes, as I believe, the especial merit of our method. Systematic lectures have of course their own high value, in giving to the student a comprehensive view of the whole range of the subject and presenting it in a more attractive and impressive form than mere reading. But they have not the same power that clinical lectures have of proving the doctrines which they teach and stamping them upon the mind. Bedside instruction, again, however excellent, can be efficiently directed only to a comparatively small number of students at once, and these varying probably from day to day, and is essentially fragmentary in character, dealing, in the main with isolated practical details. But our clinical surgical lectures, though not intended in the least to supersede patient individual labour at the bedside, afford the opportunity, which neither this nor systematic teaching has, of guiding the student by the demonstrative method to sound principles of pathology and practice, which are, after all, the most important things for him to acquire. If he have these, he can supplement otber defects in education by his own unaided efforts in after-life; but if his principles are defective, however large may be his practice, he will be ever liable to blunder.

Mr. Bryant makes the very true remark: "By no system, however good, can a bad teacher be made bright;" but I must demur entirely to the statement which he couples with it: "By no system, however bad, can a good one" (teacher) "be hampered." However great a man's gifts and zeal may be, he cannot fail to be hampered, with respect to the great object to which I have alluded if, even though he have the title of Professor of Clinical Surgery, instead of teaching twice a week his own college class in full regular attendance, he shares the duty with one or more surgical colleagues of whose doings he has no cognisance either as to the subjects that are bronght forward by them or the doctrines enunciated, and meets, it may be once a fortuight, students whom the circumstances of the chair lead to regard clinieal surgical lectures as of secondary importance, and who consequently give desultory attendance. Again, I well 
remember the difference made to my day's work in Glasg?w, when it came to be my turn, as one of the surgeons of the infirmary, to give one clinical lecture a week during the winter session, when $\mathrm{my}$ systematic lectures at the college were going on. I am, therefore, sure that anyone must be hampered as a clinical lecturer who is also charged with the duty of systematic teaching, whether of surgery or any other subject. Lastly, as regards demonstrative teaching, I need hardly say that not only will a man be hampered, but entirely prevented from acting, if in the system which prevails at his school, whether from necessity or established usage, the patients are not brought before the class in lecture at all.

Such I believe I am correct in saying were the hampering conditions under which clinical surgical lectures were ordinarily given in London when I was a student; and I am bound to repeat that, when compared with the Edinburgh system, a London chair of clinical surgery, when it did exist, which was by no means universal in the London schools, was something which fell exceedingly far short of what might be expected from its title. I do not again employ the word sham, because Mr. Smith informs me that Johnson speaks of it as a low word, although the quotations given by the lexicographer show that it was not disdained by so classical an author as Addison. Since my remarks were made, I have been informed that in some London schools patients are now introduced into the lectures by way of illustration. Thus, Mr. Heath, in a letter which appeared in the British Medical Journal of the 10th inst., states that such is the case, "as far as possible," at University College. But if I turn to a clinical lecture published by him in the Medical Examiner of the 8 th inst., I do not find evidence of any material change having taken place since my student days. And this leads me to hope that my statement has not been materially inaccurate.

It is only fair to the University of Edinburgh that $I$ should say that she allows free trade in the teaching of clinical surgery as in other subjects of the medical curriculum. The Professor of Systematic Surgery, indeed, though perfectly at liberty to give bedside instruction, is not allowed to give clinical lectures, any more than I am permitted to give systematic ones, because the two chairs are distinct, and by a rule of the University no professor is allowed to trespass on the province of a colleague. But any of the other three surgeons of the infirmary who desires to lecture clinically in either of the two extra theatres provided by the managers for the purpose is recognised by the University on the same footing as the professor, provided that he complies with the university rule of not lecturing also upon systematic surgery; the only restriction being that the student is not allowed to take the lectures of extra-academical teachers in more than four distinct subjects. Even this restriction fetters him comparatively little in such a subject as clinical surgery, because students very commonly take two or more courses, thongh only one is required by the University regulations. Hence an unprofitable professor might be left with empty benches; and, further, although in any one session a student must get his clinical lectures, like systematic ones, from one teacher only, he may vary his sources of instruction in succeeding sessions. Thus it will be seen that the method for which I contend is not, as Mr. Bryant has called it, my system, but simply that of the University of Edinburgh. Of the advantages of that system I believe no one can be fully aware who has not experienced them. Mr. Spme was undoubteily a man of very rare power as a teacher; but if we consider that he only met his class twice a week, and that, in consequence of the large number of the students and the smallness of the wards, he did not aim at doing much in the way of bedside instruction, the very remarkable inHuence which he exerted upon the Edinburgh school must certainly be attributed in part to the system on which he taught. It is, I repeat, to this alone that my remarks had reference; and, taking this into consideration, I trust your readers may see that $I$ have been neither arrogant nor unjust; while I may have unintentionally done some service by drawing attention to what seems to me a serious defect in the medical schools of London.-I am, \&c.,

Edinburgh, 24th March, 1877.

JOSEPH LISTER.

* * We regret that Mr. Lister, instead of offering an apology for the offensive remarks which he recently made respecting the character of the instruction afforded in clinical surgery at the medical schools in London, should attempt to justify them. As Mr. Lister's own version of his observations confirms the accuracy of the report upon which our strictures were based, we are not in the least affected by the main argument of his letter, which, besides being one-sided and inconsistent, is wholly irrelevant. We have no desire to make invidious comparisons between the relative advantages and disadvantages of the Edinburgh and the London medical schools, but we are interested to discover the reasons that first induced Mr. Lister to make use of the opprobrious epithet "sham," in describing the mode in which clinical surgery is taught in London, and which now make him unwilling to retract it. But as Mr. Lister nowhere shows signs of regret, we must, in charity, suppose that he fails to perceive that it is the employment of this term which has excited so much "amazement and indignation."-ED. L.

\section{THE FELLOWSHIP OF THE ROYAL COLLEGE OF SURGEONS.}

\section{To the Editor of THE LANCET.}

Sin,-The petition to the College of Surgeons has borne fruit, and the standard of the Fellowship examination will not be lowered. After the able letters you have published on the subject, your columns are, perhaps, closed to it; but I would venture to submit that the question is not yet settled.

It has been urged in objection to the Fellowship by examination, as it at present stands, that it is a degree for students. Is it, therefore, to be blamed? There are students and students; and if at the outset of their career a certain number of picked men can start in life with a high diploma, so much the better for the diploma and for them. The same objection might be raised against a high degree in mathematics at Cambridge-that it is a degree for students. The Senior Wrangler is not usually of such an age as is required in Fellows by examination. The Wranglership and the Fellowship are alike the rewards of hard work, and the tests of a larger experience. True, some of those who have obtained the Fellowship may thereafter fail ; but their failure will be to their own detriment rather than to the diploma which they bear. Are there no Senior Wranglers who, to put it tenderly,-

But die with all their music in them
"Never sing

And I think that in the long run the Fellowship examination does separate the wheat from the chaff. A distinguished gold medalist of a famous school presented himself on an occasion well known to myself. He amused some of the unrejected candidates when waiting in the "funking room" by his evident appreciation of the value of his gold medal, and by chronicling events in his life with reference to the date of his gaining it. Such an event happened three months after, such five months before, he obtained the coveted reward. I have since learned that the examiners at the College of Surgeons formed a correct estimate of this ingenuous medalist.

But is the Fellowship Examination patronised only by students? On this point we have no statistics. At my own examination two men, to my knowledge, passed; the one an able practitioner of some years' standing in the suburbs, the other, a house-surgeon at the Cumberland Infirmary, when the writer was prattling as a child.

But there are yet left those, no small numher, entitled to the Fellowship, who, by the existing regulations, must remain without it. And what I think, with all due deference, the profession has a right to ask is, that the College of Surgeons shall enlarge its borders, and into its fold shall gather all who, whether in this country or abroad, are, by known repute, deserving of the bonour. No occasion here to enter into detail. 'The Council of the College, with its large practical experience, can bave no difficulty in devising such rules as shall allow of admission to the Honorary Fellowship of men who have attained to surgical eminence, or who adorn their calling; of men who, from various circumstances, have been prevented in their student days from 